\title{
Cognitive Enhancement: Methods, Ethics, Regulatory Challenges
}

\author{
Nick Bostrom · Anders Sandberg
}

WWW. nickbostrom. com

Received: 12 August 2006/Accepted: 25 March 2009/Published online: 19 June 2009

(C) Springer Science+Business Media B.V. 2009

\begin{abstract}
Cognitive enhancement takes many and diverse forms. Various methods of cognitive enhancement have implications for the near future. At the same time, these technologies raise a range of ethical issues. For example, they interact with notions of authenticity, the good life, and the role of medicine in our lives. Present and anticipated methods for cognitive enhancement also create challenges for public policy and regulation.
\end{abstract}

Keywords Cognitive enhancement - Ethics - Human enhancement · IQ · Intelligence · Policy

\section{Introduction}

Cognitive enhancement may be defined as the amplification or extension of core capacities of the mind through improvement or augmentation of internal or external information processing systems. As cognitive neuroscience has advanced, the list of prospective internal, biological enhancements has steadily expanded (Farah et al. 2004). Yet to date, it is progress in computing and information technology that has produced the most dramatic advances in the ability to process information. ${ }^{1}$

\footnotetext{
1 Advances in social organization have also enabled individual minds - through interactions with other people's minds - to become vastly more effective. Improvements in social organization that are not directly mediated by technology lie outside the scope of this review.
}

N. Bostrom $(\bowtie) \cdot$ A. Sandberg

Future of Humanity Institute, Faculty of Philosophy \& James Martin 21st Century School, Oxford University, Littlegate House, 16/17 St Ebbes Street, Oxford OX1 1PT, UK

e-mail: nick.bostrom@philosophy.ox.ac.uk
A. Sandberg
e-mail: anders.sandberg@philosophy.ox.ac.uk 
External hardware and software supports now routinely give human beings effective cognitive abilities that in many respects far outstrip those of biological brains.

Cognition can be defined as the processes an organism uses to organize information. This includes acquiring information (perception), selecting (attention), representing (understanding) and retaining (memory) information, and using it to guide behavior (reasoning and coordination of motor outputs). Interventions to improve cognitive function may be directed at any one of these core faculties.

An intervention that is aimed at correcting a specific pathology or defect of a cognitive subsystem may be characterized as therapeutic. An enhancement is an intervention that improves a subsystem in some way other than repairing something that is broken or remedying a specific dysfunction. In practice, the distinction between therapy and enhancement is often difficult to discern, and it could be argued that it lacks practical significance. For example, cognitive enhancement of somebody whose natural memory is poor could leave that person with a memory that is still worse than that of another person who has retained a fairly good memory despite suffering from an identifiable pathology, such as early-stage Alzheimer's disease. A cognitively enhanced person, therefore, is not necessarily somebody with particularly high (let alone super-human) cognitive capacities. A cognitively enhanced person, rather, is somebody who has benefited from an intervention that improves the performance of some cognitive subsystem without correcting some specific, identifiable pathology or dysfunction of that subsystem.

The spectrum of cognitive enhancements includes not only medical interventions, but also psychological interventions (such as learned "tricks" or mental strategies), as well as improvements of external technological and institutional structures that support cognition. A distinguishing feature of cognitive enhancements, however, is that they improve core cognitive capacities rather than merely particular narrowly defined skills or domain-specific knowledge.

Most efforts to enhance cognition are of a rather mundane nature, and some have been practiced for thousands of years. The prime example is education and training, where the goal is often not only to impart specific skills or information, but also to improve general mental faculties such as concentration, memory, and critical thinking. Other forms of mental training, such as yoga, martial arts, meditation, and creativity courses are also in common use. Caffeine is widely used to improve alertness. Herbal extracts reputed to improve memory are popular, with sales of Ginko biloba alone in the order of several hundred million dollars annually in the U.S. (van Beek 2002). In an ordinary supermarket there are a staggering number of energy drinks on display, vying for consumers who are hoping to turbo-charge their brains.

Education and training, as well as the use of external information processing devices, may be labeled as "conventional" means of enhancing cognition. They are often well established and culturally accepted. By contrast, methods of enhancing cognition through "unconventional" means, such as ones involving deliberately created nootropic drugs, gene therapy, or neural implants, are nearly all to be regarded as experimental at the present time. Nevertheless, these unconventional forms of enhancements deserve serious consideration for several reasons: 
- They are relatively new, and consequently there does not exist a large body of "received wisdom" about their potential uses, safety, efficacy, or social consequences;

- They could potentially have enormous leverage (consider the cost-benefit ratio of a cheap pill that safely enhances cognition compared to years of extra education);

- They are sometimes controversial;

- They currently face specific regulatory problems, which may impede advances; and

- They may eventually come to have important consequences for society and even, in the longer run, for the future of humankind.

In examining the challenges for public policy with regard to cognitive enhancement, it is important to consider the full range of different possibilities that are becoming available, and their different individual characteristics. From such a comprehensive viewpoint, the inadequacies of some aspects of the current regulatory and policy framework become apparent, as it treats different modes of enhancement differently even though, arguably, there is no good justification for doing so.

One general caveat must be noted about the survey that follows. Many of the cognitive enhancement methods being studied today remain highly experimental or have small effect sizes. This makes the present scientific literature a weak guide to their eventual usefulness (Ioannidis 2005). Findings need to be repeated in multiple studies and larger clinical trials before they can be fully trusted. It is likely that many enhancement techniques will in the long run prove less efficacious than their current promoters claim. At the same time, the sheer range of enhancement methods suggests that it would be very unlikely that all current methods are ineffective or that future advances will fail to produce an increasingly potent toolbox for enhancing cognition.

\section{Methods of Cognitive Enhancement}

Education, Enriched Environments and General Health

Education has many benefits beyond higher job status and salary. Longer education reduces the risks of substance abuse, crime and many illnesses while improving quality of life, social connectedness, and political participation (Johnston 2004). There is also positive feedback between performance on cognitive tests such as IQ tests and scholastic achievement (Winship and Korenman 1997).

Much of what is learned in school is "mental software" for managing various cognitive domains: mathematics, categories of concepts, language, and problem solving in particular subjects. This kind of mental software reduces one's mental load through clever encoding, organization, or processing. Instead of memorizing multiplication tables, the pattern of arithmetic relationships is compressed into simpler rules of multiplication, which in turn (among very ambitious students) can be organized into efficient mental calculation methods like the Trachtenberg system (Trachtenberg 2000). Such specific methods have a narrower range of applicability 
but can dramatically improve performance within a particular domain. They represent a form of crystallized intelligence, distinct from the fluid intelligence of general cognitive abilities and problem solving capacity (Cattell 1987). The relative ease and utility of improving crystallized intelligence and specific abilities have made them popular targets of internal and external software development. Enhancement of fluid intelligence is more difficult.

Pharmacological cognitive enhancements (nootropics) have physiological effects on the brain. So, too, do education and other conventional interventions. In fact, conventional interventions often produce more permanent neurological changes than do drugs. Learning to read alters the way language is processed in the brain (Petersson 2000). Enriched rearing environments have been found to increase dendritic arborisation and to produce synaptic changes, neurogenesis, and improved cognition in animals (Walsh et al. 1969; Greenoug and Volkmar 1973; Diamond et al. 1975; Nilsson et al. 1999). While analogous controlled experiments cannot easily be done for human children, it is very likely that similar effects would be observed. Stimulation-seeking children, who might be seeking out and creating enriched environments for themselves, score higher on IQ tests and do better at school than less stimulation-seeking children (Raine et al. 2002). This also suggests that interventions, whether environmental or pharmaceutical, that make exploring and learning more appealing to children might improve cognition.

Enriched environments also make brains more resilient to stress and neurotoxins (Schneider et al. 2001). Reducing neurotoxins and preventing bad prenatal environments are simple and widely accepted methods of improving cognitive functioning. These kinds of intervention might be classified as preventative or therapeutic rather than enhancing, but the distinction is blurry. For instance, an optimized intrauterine environment will not only help avoid specific pathology and deficits but is also likely to promote the growth of the developing nervous system in ways that enhance its core capacities.

In brains that have already been damaged, e.g. by lead exposure, nootropics may alleviate some of the cognitive deficits (Zhou and Suszkiw 2004). It is not always clear whether they do so by curing the damage or by amplifying (enhancing) capacities that compensate for the loss, or whether the distinction is even always meaningful. Comparing chronic exposure to cognition-enhancing drugs with an enriched rearing environment, one study in rats found that both conditions improved memory performance and produced similar changes in the neural matter (Murphy et al. 2006). The improvements in the drug-treated group persisted even after cessation of treatment. The combination of drugs and enriched environment did not improve the rats' abilities beyond the improvement provided by one of the interventions alone. This suggests that both interventions produced a more robust and plastic neural structure capable of learning more efficiently.

Improving general health has cognition-enhancing effects. Many health problems act as distracters or directly impair cognition (Schillerstrom et al. 2005). Improving sleep, immune function, and general conditioning promotes cognitive functioning. Bouts of exercise have been shown to improve temporarily various cognitive capacities, the size of the effect depending on the type and intensity of the exercise (Tomporowski 2003). Long-term exercise also improves cognition, possibly 
through a combination of increased blood supply to the brain and the release of nerve growth factors (Vaynman and Gomez-Pinilla 2005).

\section{Mental Training}

Mental training and visualization techniques are widely practiced in elite sport (Feltz and Landers 1983) and rehabilitation (Jackson et al. 2004), with apparently good effects on performance. Users vividly imagine themselves performing a task (running a race, going to a store), repeatedly imagining every movement and how it would feel. A likely explanation for the efficacy of such exercises is that they activate the neural networks involved in executing a skill at the same time as the performance criteria for the task is held in close attention, optimizing neural plasticity and appropriate neural reorganization.

General mental activity_ "working the brain muscle"-can improve performance (Nyberg et al. 2003) and long-term health (Barnes et al. 2004), while relaxation techniques can help regulate the activation of the brain (Nava et al. 2004). It has been suggested that the Flynn-effect (Flynn 1987), a secular increase in raw intelligence test scores by 2.5 IQ points per decade in most western countries, is attributable to increased demands of certain forms of abstract and visuospatial cognition in modern society and schooling, although improved nutrition and health status may also play a part (Neisser 1997; Blair et al. 2005). On the whole, however, the Flynn effect seems to reflect a change in which specific forms of intelligence are developed, rather than an increase in general fluid intelligence.

The classic form of cognitive enhancement software consists of learned strategies to memorize information. Such methods have been used since antiquity with much success (Yates 1966; Patten 1990). One such classic strategy is "the method of loci". The user visualizes a building, either real or imaginary, and in her imagination she walks from room to room, depositing imaginary objects that evoke natural associations to the subject matter that she is memorizing. During retrieval, the user retraces her imaginary steps, and the sequence of memorized information is recalled when she "sees" the objects she placed along the route. This technique harnesses the brain's spatial navigation system to remember objects or propositional contents. Other memory techniques make use of rhyming or the fact that one more easily recalls dramatic, colorful, or emotional scenes, which can serve as proxies for items that are more difficult to retain, such as numbers or letters. The early memory arts were often used as a substitute for written text or to memorize speeches. Today, memory techniques tend to be used in service of everyday needs such as remembering door codes, passwords, shopping lists, and by students who need to memorize names, dates, and terms when preparing for exams (Minninger 1997; Lorrayne 1996).

One study which compared exceptional memorizers (participants in the World Memory Championships) with normal subjects found no systematic differences in brain anatomy (Maguire et al. 2003). However, it found differences in activity patterns during memorization, likely reflecting the use of a deliberate encoding strategy. Areas of the brain involved in spatial representation and navigation were disproportionately activated in the skilled memorizers, regardless of whether the items to be memorized were numbers, faces, or the shapes of snowflakes. Asked 
about their memory strategies, nearly all the memorizers reported using the method of loci.

In general, it is possible to attain very high memory performance on specific types of material using memory techniques. They provide the greatest performance enhancement for meaningless or unrelated information, such as sequences of numbers, but they do not appear to help in complex everyday activities (Ericsson 2003).

There exists a vast array of mental techniques alleged to boost various skills, such as creativity training, speed reading methods (Calef et al. 1999), and mind-maps (Buzan 1982; Farrand et al. 2002). It is unclear how widespread the use of such techniques is, and in most cases there is a lack of good data about their efficacy. Even if a technique improves performance on some task under laboratory conditions, it does not follow that the technique is practically useful. In order for a technique to significantly benefit a person, it would have to be effectively integrated into daily life.

\section{Drugs}

Stimulant drugs such as nicotine and caffeine have long been used to improve cognition. In the case of nicotine a complex interaction with attention and memory occurs (Warburton 1992; Newhouse et al. 2004; Rusted et al. 2005), while caffeine reduces tiredness (Lieberman 2001; Smith et al. 2003; Tieges et al. 2004). In more recent years, a wide array of drugs have been developed that affect cognition (Farah et al. 2004).

Lashley observed in 1917 that strychnine facilitates learning in rats (Lashley 1917). Since then several families of memory enhancing drugs affecting different aspects of long-term memory have been discovered. They include stimulants (Lee and Ma 1995; Soetens et al. 1993; Soetens et al. 1995), nutrients (Korol and Gold 1998; Foster et al. 1998; Meikle et al. 2005; Winder and Borrill 1998) and hormones (Gulpinar and Yegen 2004), cholinergic agonists (Iversen 1998; Power et al. 2003; Freo et al. 2005), the piracetam family (Mondadori 1996), ampakines (Lynch 1998; Ingvar et al. 1997), and consolidation enhancers (Lynch 2002).

Diet, and dietary supplements, can affect cognition. In order to maintain optimal functioning, the brain requires a continuous supply of glucose, its major energy source (Fox et al. 1988). Increases in glucose availability, from the ingestion of sugars or the release of the acute stress hormone norepinephrine, improve memory (Wenk 1989; Foster et al. 1998), with the effects being particularly pronounced in demanding tasks (Sunram-Lea et al. 2002). Creatine, a nutrient that improves energy availability, also appears to benefit overall cognitive performance (Rae et al. 2003) and reduce mental fatigue (Watanabe et al. 2002; McMorris et al. 2006). Besides being an energy source, food can contribute to cognition by providing amino acids needed in the production of neurotransmitters, which is particularly important during periods of stress or sustained concentration (Banderet and Lieberman 1989; Deijen et al. 1999; Lieberman 2003). There is also evidence that micronutrient supplementation increases nonverbal intelligence in some children. This effect might be due to correction of occasional deficiencies rather than a general enhancing action (Benton 2001).

Stimulants enhance memory by increasing neuronal activation or by releasing neuromodulators, facilitating the synaptic changes that underlie learning. The 
earliest enhancer drugs were mainly nonspecific stimulants and nutrients. In antiquity, for example, honey water (hydromel) was used for doping purposes (Berriman 1962).

Advances in the scientific understanding of memory enabled the development of drugs with more specific actions, such as drugs stimulating the cholinergic system, which appears to gate attention and memory encoding. Current interest is focused on intervening in the process of permanent encoding in the synapses, a process which has been greatly elucidated in recent years and is a promising target for drug development. The goal is to develop drugs that not only allow the brain to learn quickly, but which also facilitate selective retention of the information that has been learned. Several experimental substances have been shown to improve performance in particular memory tests. It is not yet known whether these drugs also promote useful learning in real-life situations, but beneficial enhancement of memory through pharmacological means is likely to be possible.

Pharmacological agents might be useful not only for increasing memory retention but also for unlearning phobias and addictions (Pitman et al. 2002; Hofmann et al. 2006; Ressler et al. 2004). Potentially, the combination of different drugs administered at different times could give users a more fine-grained control of their learning processes, perhaps even the ability to deliberately select specific memories that they want to retain or get rid of.

Even common, traditional and unregulated herbs and spices such as sage can improve memory and mood through chemical effects (Kennedy et al. 2006). While less powerful than those of dedicated cholinesterase inhibitors, such effects illustrate that attempts to control access to cognition-enhancing substances would be problematic. Even chewing gum appears to affect memory, possibly by heightening arousal or blood sugar (Wilkinson et al. 2002).

Working memory can be modulated by a variety of drugs. Drugs that stimulate the dopamine system have demonstrated effects, as do cholinergic drugs (possibly through improved encoding) (Barch 2004). Modafinil has been shown to enhance working memory in healthy test subjects, especially at harder task difficulties and for lower-performing subjects (Muller et al. 2004). (Similar findings of stronger improvements among low performers were also seen among the dopaminergic drugs, and this might be a general pattern for many cognitive enhancers.) Modafinil has been found to increase forward and backward digit span, visual pattern recognition memory, spatial planning, and reaction time/latency on different working memory tasks (Turner et al. 2003). The mode of action of this drug is not yet understood, but part of what seems to happen is that modafinil enhances adaptive response inhibition, making the subjects evaluate a problem more thoroughly before responding, thereby improving performance accuracy. The working memory effects might thus be part of a more general enhancement of executive function.

Modafinil was originally developed as a treatment for narcolepsy, and can be used to reduce performance decrements due to sleep loss with apparently small side effects and little risk of dependency (Teitelman 2001; Myrick et al. 2004). The drug improved attention and working memory in sleep-deprived physicians (Gill et al. 2006) and aviators (Caldwell et al. 2000). Naps are more effective in maintaining performance than modafinil and amphetamine during long $(48 \mathrm{~h})$ periods of sleep 
deprivation, while the reverse holds for short $(24 \mathrm{~h})$ periods of sleep deprivation. Naps followed by a modafinil dose may be more effective than either one on its own (Batejat and Lagarde 1999). These results, together with studies on hormones like melatonin which can control sleep rhythms (Cardinali et al. 2002), suggest that drugs can enable fine-tuning of alertness patterns to improve task performance under demanding circumstances or disturbed sleep cycles.

There also exist drugs that influence how the cerebral cortex reorganizes in response to damage or training. Noradrenergic agonists such as amphetamine have been shown to promote faster recovery of function after a brain lesion when combined with training (Gladstone and Black 2000), and to improve learning of an artificial language (Breitenstein et al. 2004). A likely explanation is that higher excitability increases cortical plasticity, in turn leading to synaptic sprouting and remodeling (Stroemer et al. 1998; Goldstein 1999). An alternative to pharmacologic increase of neuromodulation is to electrically stimulate the neuromodulatory centers that normally control plasticity through attention or reward. In monkey experiments this produced faster cortical reorganization (Bao et al. 2001; Kilgard and Merzenich 1998).

\section{Transcranial Magnetic Stimulation}

Transcranial magnetic stimulation (TMS) can increase or decrease the excitability of the cortex, thereby changing its level of plasticity (Hummel and Cohen 2005). TMS of the motor cortex that increased its excitability improved performance in a procedural learning task (Pascual-Leone et al. 1999). TMS in suitable areas has also been found beneficial in a motor task (Butefisch et al. 2004), motor learning (Nitsche et al. 2003), visuo-motor coordination tasks (Antal et al. 2004a, b), working memory (Fregni et al. 2005), finger sequence tapping (Kobayashi et al. 2004), classification (Kincses et al. 2004) and even declarative memory consolidation during sleep (Marshall et al. 2004). Alan Snyder and colleagues claim to have demonstrated how TMS inhibiting anterior brain areas could change the drawing style of normal subjects into a more concrete style and improve spell-checking abilities, presumably by reducing top-down semantic control (Snyder et al. 2003; Snyder 2004). While TMS appears to be quite versatile and non-invasive, there are risks of triggering epileptic seizures, and the effects of long-term use are not known. Moreover, individual brain differences may necessitate much adjustment before it can be used to improve specific cognitive capacities. It is still doubtful whether TMS will ever be a practically useful enhancement method.

\section{Genetic Modifications}

Genetic memory enhancement has been demonstrated in rats and mice. During the maturation of normal animals, synthesis of the NR2B subunit of the NMDA receptor is gradually replaced with synthesis of the NR2A subunit. This might be linked to the lower brain plasticity of adult animals. Joe Tsien and co-workers modified mice to produce more of the NR2B subunits. The NR2B "Doogie" mice 
showed improved memory performance, in terms of both acquisition and retention (Tang et al. 1999). This included unlearning of fear conditioning, which is believed to be due to the learning of a secondary memory (Falls et al. 1992). The modification also made the mice more sensitive to certain forms of pain (Wei et al. 2001), suggesting a non-trivial trade-off between two potential enhancement goals-better memory and less pain, in this particular case.

Increased amounts of brain growth factors (Routtenberg et al. 2000) and the signal transduction protein adenylyl cyclase (Wang et al. 2004) have also produced memory improvements. These modifications had different enhancing effects. Unlearning took longer for these modified mice than for unmodified mice, while the mice in the abovementioned Tsien study had faster than normal unlearning. Different memory tasks were also differently affected: the cyclase mice had enhanced recognition memory but not improved context or cue learning. Another study found that mice with a deleted cbl-b gene had normal learning but enhanced long-term retention, presumably indicating that the gene is a negative regulator of memory whose removal reduced forgetting (Tan et al. 2006). These enhancements may be due to changes in neural plasticity during the learning task itself, or to ontogenetic changes in brain development that promote subsequent learning or retention.

The cellular machinery of memory appears to be highly conserved in evolution, making interventions demonstrated to work in animal models likely to have close counterparts in humans (Bailey et al. 1996; Edelhoff et al. 1995).

Genetic studies have also found genes in humans whose variations account for up to 5\% of memory performance (de Quervain and Papassotiropoulos 2006). These include the genes for the NMDA receptor and adenylyl cyclase that were mentioned above, as well as genes involved in other stages of the synaptic signal cascade. These are obvious targets for enhancement.

Given these early results, it seems likely that there exist many potential genetic interventions that would directly or indirectly improve aspects of memory. If it turns out that the beneficial effects of the treatments are not due to changes in development, then presumably some of the effects can be achieved by supplying the brain with the substances produced by the memory genes without resorting to genetic modification. But genetic modification would make the individual independent of an external drug supply and would guarantee that the substances end up in the right place.

Studies of the genetics of intelligence suggest that there is a large number of genetic variations affecting individual intelligence, but each accounting for only a very small fraction $(<1 \%)$ of the variance between individuals (Craig and Plomin 2006). This would indicate that genetic enhancement of intelligence through direct insertion of a few beneficial alleles is unlikely to have a big enhancing effect. It is possible, however, that some alleles that are rare in the human population could have larger effects on intelligence, both negative and positive. ${ }^{2}$

\footnotetext{
${ }^{2}$ A possible example is suggested in (Cochran et al. 2006), where it is predicted that heterozygoticity for Tay-Sachs' disease should increase IQ by about 5 points.
} 


\section{Prenatal and Perinatal Enhancement}

A notable form of chemical enhancement is pre- and perinatal enhancement. Administering choline supplementation to pregnant rats improved the performance of their pups, apparently as a result of changes in neural development (Meck et al. 1988; Mellott et al. 2004). Given the ready availability of choline supplements, such prenatal enhancement may already (inadvertently) be taking place in human populations. Supplementation of a mother's diet during late pregnancy and 3 months postpartum with long chained fatty acids has also been shown to improve cognitive performance in human children (Helland et al. 2003). Deliberate changes of maternal diet might be regarded as part of the cognitive enhancement spectrum. At present, recommendations to mothers are mostly aimed at promoting a diet that avoids specific harms and deficits, but the growing emphasis on boosting "good fats" and the use of enriched infant formulas point towards enhancement.

\section{External Hardware and Software Systems}

Some approaches in human-computer interaction are explicitly aimed at cognitive enhancement (Engelbart 1962). External hardware is of course already used to amplify cognitive abilities, be it pen and paper, calculators, or personal computers. Many common pieces of software act as cognition-enhancing environments, where the software helps display information, keep multiple items in memory, and perform routine tasks. Data mining and information visualization tools process and make graspable enormous amounts of data that human perceptual systems cannot handle. Other tools such as expert systems, symbolic math programs, decision support software, and search agents amplify specific skills and capacities.

What is new is the growing interest in creating intimate links between the external systems and the human user through better interaction. The software becomes less an external tool and more of a mediating "exoself". This can be achieved through mediation, embedding the human within an augmenting "shell" such as wearable computers (Mann 2001; Mann and Niedzviecki 2001) or virtual reality, or through smart environments in which objects are given extended capabilities. An example is the vision of "ubiquitous computing", in which objects would be equipped with unique identities and given the ability to communicate with and actively support the user (Weiser 1991). A well-designed environment can enhance proactive memory (Sellen et al. 1996) by deliberately bringing previous intentions to mind in the right context.

Another form of memory-enhancing exoself software is remembrance agents (Rhodes and Starner 1996), software agents that act as a vastly extended associative memory. The agents have access to a database of information such as a user's files, email correspondence, etc., which they use to suggest relevant documents based on the current context. Other exoself applications include additions to vision (Mann 1997), team coordination (Fan et al. 2005a, b), face recognition (Singletary and Starner 2000), mechanical prediction (Jebara et al. 1997), and the recording of emotionally significant events (Healey and Picard 1998). 
Given the availability of external memory support, from writing to wearable computers, it is likely that the crucial form of memory demand on humans in the future will increasingly be the ability to link information into usable concepts, associations, and skills rather than the ability to memorize large amounts of raw data. Storage and retrieval functions can often be offloaded from the brain, while the knowledge, strategies, and associations linking the data to skilled cognition cannot so far be outsourced to computers to the same extent.

\section{Brain-Computer Interfaces}

Wearable computers and PDAs (personal digital assistants) are already intimate devices worn on the body, but there have been proposals for even tighter interfaces. Direct control of external devices through brain activity has been studied with some success for the last 40 years, although it remains a very low bandwidth form of signalling (Wolpaw et al. 2000).

The most dramatic potential internal hardware enhancements are brain-computer interfaces. Development is rapid, both on the hardware side, where multielectrode recordings from more than 300 electrodes permanently implanted in the brain are currently state-of-the art, and on the software side, with computers learning to interpret the signals and commands (Nicolelis et al. 2003; Shenoy et al. 2003; Carmena et al. 2003). Early experiments on humans have shown that it is possible for profoundly paralyzed patients to control a computer cursor using just a single electrode (Kennedy and Bakay 1998) implanted in the brain, and experiments by Parag Patil and colleagues have demonstrated that the kind of multielectrode recording devices used in monkeys would most likely also function in humans (Peterman et al. 2004; Patil et al. 2004). Experiments in localized chemical release from implanted chips also suggest the possibility of using neural growth factors to promote patterned local growth and interfacing (Peterman et al. 2004).

Cochlear implants are already widely used, and there is ongoing research in artificial retinas (Alteheld et al. 2004) and functional electric stimulation for paralysis treatment (von Wild et al. 2002). These implants are intended to ameliorate functional deficits and are unlikely to be attractive for healthy people in the foreseeable future. However, the digital parts of the implant could in principle be connected to any kind of external software and hardware. This could enable enhancing uses such as access to software tools, the Internet, and virtual reality applications. In a demonstration project, a healthy volunteer has been given the ability to control a robotic arm using tactile feedback, both in direct adjacency and remotely, and to perform simple direct neural communication with another implant (Warwick et al. 2003). Non-disabled people, however, could most likely achieve the essentially same functionality more cheaply, safely, and effectively through eye, finger, and voice control.

\section{Collective Intelligence}

Much of human cognition is distributed across many minds. Such distributed cognition can be enhanced through the development and use of more efficient tools and methods of intellectual collaboration. The World Wide Web and e-mail are 
among the most powerful kinds of cognitive enhancement software developed to date. Through the use of such social software, the distributed intelligence of large groups can be shared and harnessed for specific purposes (Surowiecki 2004).

Connected systems allow many people to collaborate in the construction of shared knowledge and solutions. Usually, the more individuals that connect, the more powerful the system becomes (Drexler 1991). The information in such systems is stored not just in individual documents but also in their interrelations. When such interconnected information resources exist, automated systems such as search engines (Kleinberg 1999) can often radically improve the ability to extract useful information from them.

Lowered coordination costs enable larger groups to work on common projects. Groups of volunteers with shared interests, such as amateur journalist "bloggers" and open source programmers, have demonstrated that they can successfully complete large and highly complex projects, such as online political campaigns, the Wikipedia encyclopedia, and the Linux operating system. Systems for online collaboration can incorporate efficient error correction (Raymond 2001; Giles 2005), enabling incremental improvement of product quality over time.

One powerful technique of knowledge aggregation is prediction markets (also known as "information markets" or "idea futures markets"). In such a market, participants trade in predictions of future events. The prices of these bets tend to reflect the best information available about the probability of whether the events will occur (Hanson et al. 2003). Such markets appear to be self-correcting and resilient, and have been shown to outperform alternative methods of generating probabilistic forecasts, such as opinion polls and expert panels (Hanson et al. 2006).

\section{Ethical Issues}

\section{Safety}

Safety concerns tend to focus on medical risks of internal biological enhancements. Yet risks accompany any intervention, not just biomedical procedures. External software enhancements raise safety issues such as privacy and data protection. Similar issues can arise in some enhancements focusing on collaborative intelligence. The latter might also create unique kinds of risks arising from emergent phenomena in large networks of interacting agents-witness the "flame wars" into which some email lists are prone to erupt, creating stress and unpleasantness for everyone involved. Psychological techniques and training are generally regarded as safe, but to the extent that their long-term use have significant effects on neural organization, they can pose subtle but substantial risks to the user.

Even education is a risky enhancement method. Education can enhance cognitive skills and capacities, but it can also create fanatics, dogmatists, sophistic arguers, skilled rationalizers, cynical manipulators, and indoctrinated, prejudiced, confused, or selfishly calculating minds. Even high-quality education that includes training in formal methods and critical thinking can have problematic effects. For instance, several studies indicate that the study of economics makes students on average more 
selfish than they were before (Frank et al. 1993; Rubinstein 2005). [Higher education may also increase the risk of becoming a professor or university don-a profession characterized by E. Friedell as involving "a slow metabolism, a sluggish bowel, a penchant for gradualist doctrines, and pedantry" (Kolnai 1976).]

One could argue that the risks from education are fundamentally different from certain other categories of risk, such as medical risks. A student who becomes a fanatic or selfishly calculating does so, one argument runs, through their own choice and their deliberate acceptance of, or reaction to, the taught material. In contrast, a drug's action on the nervous system is more direct, unmediated by propositional beliefs or conscious deliberation. This argument, however, is not entirely convincing. Educational enhancements are widely applied to subjects who are too young to give informed consent to the procedure, and who are unable critically to evaluate what they are being taught. Even among more advanced students, it is implausible that all the effects of education are mediated by rational deliberation. Much is simply "absorbed" through subconscious emulation and as a side-effect of how information is presented. Cognitive habits and inclinations acquired from education often have life-long sequelae.

Nevertheless, it is in the area of medical enhancement that safety issues are likely to be most salient. Since the current medical risk system is based on comparing treatment risk with the expected benefit of reduced morbidity risk from successful treatment, it is strongly risk averse in the case of enhancements that do not reduce morbidity risk and whose utility to the patient may be entirely non-therapeutic, highly subjective, and context dependent. Yet precedents for a different risk model can be found, for example in the use of cosmetic surgery. The consensus is that patient autonomy overrides at least minor medical risks even when the procedure does not reduce or prevent morbidity. A similar model could be used in the case of medical cognitive enhancements, with the user being allowed to decide whether the benefits outweigh the potential risks, based on advice from medical professionals and her own estimates of how the intervention might affect her personal goals and her way of life. The risks of chronic use of a cognition enhancing drug include the possibility of both medical side effects and effects more directly tied to the drug's intended function. For instance, a memory enhancer could, by exerting its intended effect, increase the number of trivial "junk" memories retained, which might be undesirable. It will often not be possible accurately to quantify these potential risks of long-term use beforehand, so there is a limit to how much guidance a user can expect to obtain from medical experts. Nor are medical experts necessarily in a position to judge whether, for a particular user, the benefits are worth the risks.

The development of cognitive enhancers may also face problems in terms of acceptable risk to test subjects. The reliability of research is another issue. Many of the cognition-enhancing interventions show small effect sizes. This may necessitate very large epidemiological studies, possibly exposing large groups to unforeseen risks.

Some enhancements may make humans dependent on outside technology, infrastructure, or drugs. If the supply is interrupted, users may suffer withdrawal symptoms or impairments. Is this sufficient reason to discourage some enhancements? Is a life dependent on external support structures less worth living, or less dignified, than an independent, unassisted, or more "natural" life? (If so, then agriculture may have been a great mistake.) 
One common concern about enhancements in the biomedical sphere is that they go beyond the purpose of medicine. The debate over whether it is possible to draw a line between therapy and enhancement, and if so where, is extensive. Regardless of this, it is clear that medicine does encompass many treatments not intended to cure, prevent, or ameliorate illness, such as plastic surgery and contraceptive medication, which are accepted. There are also many forms of enhancement that do not fit into the medical framework, such as psychological techniques and diet, but which nevertheless produce medical effects. Even if a boundary between therapy and enhancement could be agreed, it is unclear that it would have any normative significance.

A related concern is that resorting to medical or technological "fixes" will become a displacement for efforts to confront deeper social of personal problems. This concern has surfaced particularly with regard to Ritalin and other medications developed to treat attention-deficit hyperactivity disorder (ADHD). These medications can function as cognitive enhancers in healthy subjects, but their widespread use in the school-aged population in the U.S. has sparked fierce debates, with some arguing that these medications are often used to paper over the failings of the education system by making rowdy boys calmer instead of developing teaching methods that can accommodate a wider range of individual learning styles and needs. However, if modern society requires much more study and intellectual concentration than was typical for the human species in its environment of evolutionary adaptation, then it is unsurprising that many people today struggle to meet the demands of the school or the workplace. Technological self-modification and the use of cognitive enhancement methods can be seen as an extension of the human species' ability to adapt to its environment.

Enhancements for Minors and Incompetent Individuals

Young children are not in a position to give informed consent for medical interventions. The same holds true for individuals with severe mental disability, and for non-human animals. Who should be making decisions about the use of enhancement on behalf of incompetent subjects? On what grounds should these decisions be made? Is there a special obligation to help some incompetent subjects become competent agents capable of autonomous reasoning? One might also ask, supposing it became technologically feasible, whether some animals (such as the great apes) ought to be given cognitive enhancements ("uplifted") to enable them to function at a level closer to that of normal humans.

\section{Procreative Choice and Eugenics}

Some enhancements do not increase the capacity of any existing being but rather cause a new person to come into existence with greater capacities than some other possible person would have had who could have come into existence instead. This is what happens in embryo selection (Glover 1984). At present, preimplantation 
genetic diagnosis is used mainly to select out embryos with genetic disease, and occasionally for the purpose of sex selection. In the future, however, it might become possible to test for a variety of genes known to correlate with desirable attributes, including cognitive capacity. Genetic engineering might also be used to remove or insert genes into a zygote or an early embryo. In some cases, it might be unclear whether the outcome is a new individual or the same individual with a genetic modification.

It has been argued that when parents are able to do so without significant cost or inconvenience to themselves, they have an obligation to select-out of the possible children they could have-the one that they judge would have the best prospects of having a good life. This has been termed the Principle of Procreative Beneficence (Savulescu 2001).

Critics of genetic enhancements have asserted that the creation of "designer babies" will corrupt parents, who will come to view their children as mere products, subject to being evaluated according to standards of quality control rather than unconditionally accepted and loved. Is society prepared to sacrifice on the altar of consumerism even those deep values that are embodied in traditional relationships between child and parents? Is the quest for perfection worth this cultural and moral cost (Kass 2002)? There is, however, currently no clear evidence for the hypothesis that parents making use of enhancement options in procreation would become incapable of accepting and loving their children. When in vitro fertilization was first introduced, bioconservative critics predicted similar psychological harms which, fortunately, did not materialize.

Some disability advocates have voiced concern that genetic enhancement could express a negative attitude to people with disabilities, who might face increased discrimination as a result. This objection appears to apply equally to the use of preimplantation genetic diagnosis to screen embryos for genetic abnormalities, in that abnormal embryos are seen as unworthy of being allowed to develop.

Some have argued that genetic selection and genetic enhancement would constitute a kind of "tyranny of the living over the unborn" (Jonas 1985). Others have responded that a child is no freer if her genes are determined by chance than if they are determined by parental choice. Furthermore, some enhancements would increase the offspring's capacity for autonomous agency (Bostrom 2005).

There are also questions about the relationship between germ-line interventions and the now discredited eugenics programs of the last century. Other interventions that may affect the next generation, such as prenatal surgery, improvements in maternal nutrition, and screening for genetic abnormalities, have not, however, evoked the same concerns. It is important to determine the reason for this, and to examine whether there are ethically relevant differences between what may appear to be simply various means to the same end. Contemporary defenders of so-called "liberal eugenics" emphasize that they are not supporting coercive state programs but rather that parents should be allowed to make these choices themselves and that procreative freedom must be protected (Agar 2004). Several issues still arise here, such as whether the state should subsidize enhancements for parents who cannot afford them, and what protection against harmful interventions the state could impose without unduly infringing on reproductive liberty. 


\section{Authenticity}

The issue of authenticity has many sides. One is the idea that native or achieved excellence has a higher worth than talent that is bought. If cognitive abilities are for sale, in the form of a pill or some external aid, would that reduce their value and make them less admirable? Would it in some sense make the abilities less genuine? Related to this, one might think that if excellence is achieved mostly through hard work, then genetic differences and parental class play a smaller role in determining success. Yet, if there were shortcuts to excellence, then access to such shortcuts would instead become the determining factor of success and failure.

In many cases, however, shortcuts to excellence are tolerated. Society does not denounce athletes for wearing protective (and performance enhancing) shoes, since they enable the athletes to concentrate on interesting talents rather than on developing thick soles. In many elementary schools, calculators are disallowed in mathematics lessons, where the goal is to understand basic arithmetic, but they are allowed and increasingly necessary in the higher grades. The basics have by then been mastered, and the goal becomes to understand more advanced topics. These examples illustrate that cognitive enhancement aimed at extending and completing a person's talents may promote authenticity by offloading irrelevant, repetitive, or boring tasks and enabling a person to concentrate on more complex challenges that relate in more interesting ways to his or her goals and interests.

Another side of the authenticity issue is the extent to which "free choices" are manipulated by advertisers or are slavishly bound to reigning fashions by the desire to conform in order to gain social acceptance. If enhancements are added to the "must-haves" of a modern consumer, does that mean that people's bodies and minds/an individual's body and mind would come even more directly under the dominion of external and therefore "inauthentic" drivers than is currently the case? Some critics see human enhancement in general as expressive of a technocratic mindset, which threatens to "flatten our souls", sap an individual's moral fiber, lower aspirations, weaken love and attachments, lull spiritual yearnings, undermine dignity, and as likely to lead to trite consumerism, homogenization, and a Brave New World (The President's Council on Bioethics 2003). While these fears appear to be triggered less by the prospect of cognitive enhancement than by other possible forms of human enhancement or modification (e.g. of mood and emotion), they do reflect a general unease about making "the essence of human nature" a project of technological mastery (Kass 2002).

To some extent, these are cultural, social, and political issues rather than purely ethical ones. A blinkered pursuit of shallow or misguided ends is not the only way in which enhancement options could be used. If there were a widespread tendency to use the options in that way, then the problem would probably lie in the culture. The criticism is a criticism of mediocrity and bad culture rather than of enhancement tools. Many of the negative consequences of enhancement may be avoided or changed in different social contexts. Critics could argue that we have to look at the culture we have, not some ideal alternative, or that there are particular attributes of the technologies which will inevitably promote the erosion of human values. 
Again, however, cognitive enhancements have the potential to play a positive role. Insofar as cognitive enhancements amplify the capacities required for autonomous agency and independent judgment, they can help a person lead a more authentic life by enabling one to base choices on more deeply considered beliefs about unique circumstances, personal style, ideals, and the options available.

\section{Hyper-Agency, Playing God, and the Status Quo}

The concern about "hyper-agency" is in a sense opposite to the concern about authenticity. Here, the issue is that as human beings become more able to control their lives and themselves, they also become more responsible for the results and less constrained by traditional limits. The "playing God" objection asserts that human wisdom is insufficient to manage this freedom. Whether hyper-agency is a problem or not depends on both an analysis of the ethical implications of increased agency (such as the burden of responsibility for previously uncontrollable events, and the potential for increased autonomy) and the psychological and sociological question of how humans would in fact react to their increased degrees of freedom, power, and responsibility. ${ }^{3}$ The policy challenge might be to ensure that there are adequate safeguards, regulations, and transparency to support a society of increasingly cognitively resourceful individuals, and also to moderate unrealistic expectations of infallibility.

Another version of the playing God argument asserts that it is sometimes better to respect "the Given" than to try to better things using human abilities (Sandel 2002, 2004). ${ }^{4}$ The claim that society should stick with the status quo can be based on a religious sensibility, the idea that humans literally risk offending God if they overstep their mandate here on Earth. It can also be based on a less theologically articulated feeling that the proper approach to the world is one of humility and that enhancement would upset the moral or practical order of things; or, alternatively, on an explicitly conservative vision according to which the existing state of affairs has, due to its age, acquired some form of optimality. Since human agency is already interfering with the natural order in many ways that are universally accepted (for example, by curing the sick), and since society and technology have always been changing and often for the better, the challenge for this version of the playing God argument is to determine which particular kinds of interventions and changes would be bad.

One recent paper has examined the extent to which opposition to cognitive enhancement is the result of a status quo bias, defined as an irrational or inappropriate preference for the status quo just because it is the status quo. When this bias is removed, through the application of a method which the authors call "the Reversal Test", many consequentialist objections to cognitive enhancements are revealed to be highly implausible (Bostrom and Ord 2006).

\footnotetext{
3 "In my view, the fear of hyper-agency is misplaced; society as a whole seems always to return to the reasonable use of new knowledge. ... Just as most people don't drink all the liquor in their liquor cabinet...our society will absorb new memory drugs according to each individual's underlying philosophy and sense of self" (Gazzaniga 2005).

${ }^{4}$ But see also "What is and is not wrong with enhancement", a critique by Frances Kamm (2006).
} 
Cheating, Positional Goods, and Externalities

On some campuses it is now not uncommon for students to take Ritalin when preparing for exams (not to mention caffeine, glucose snacks, and energy drinks). Does this constitute a form of cheating akin to illicit doping in the Olympics? Or should students be positively encouraged to take performance enhancers (assuming they are sufficiently safe and efficacious) for the same reasons that they are encouraged to take notes and to start revising early?

Whether an action constitutes cheating depends on the agreed game rules for different activities. To pick up the ball with one's hands is cheating in golf and soccer, but not in handball or American football. If school is to be regarded as a competition for grades, then enhancers would arguably be cheating if not everyone had access to enhancements or if they were against the official rules. If school is viewed as having primarily a social function, then enhancement might be irrelevant. But if school is seen as being significantly about the acquisition of information and learning, then cognitive enhancements may have a legitimate and useful role to play.

A positional good is one whose value is dependent on others not having it. If cognitive enhancements were purely positional goods, then the pursuit of such enhancements would be a waste of time, effort, and money. People might become embroiled in a cognitive "arms race", spending significant resources merely in order to keep up with the Joneses. One person's gain would produce an offsetting negative externality of equal magnitude, resulting in no net gain in social utility to compensate for the costs of the enhancement efforts.

Most cognitive functions, however, are not purely positional goods (Bostrom 2003). They are also intrinsically desirable: their immediate value to the possessor does not entirely depend on other people lacking them. Having a good memory or a creative mind is normally valuable in its own right, whether or not other people also possess similar excellences. Furthermore, many cognitive capacities also have instrumental value, both for individuals and for society. Society faces many pressing problems which would be more readily solved if its members were smarter, wiser, or more creative. An enhancement that enables an individual to solve some of society's problems would produce a positive externality: in addition to benefits for the enhanced individual, there would be spillover benefits for other members of society.

Nevertheless, competitive aspects of enhancements should be taken into account when assessing the impact they might have on society. An enhancement may be entirely voluntary and yet become difficult to avoid for those who do not desire it. It has been suggested that many people would prefer to fly with airlines or go to hospitals where the personnel take alertness-enhancing drugs. Such preferences could expand employment opportunities for those willing to enhance themselves. Economic competition might eventually force people to use enhancements on pain of rendering themselves ineligible for certain jobs (Chatterjee 2004).

The case might be compared to that of literacy, which is also forced upon citizens in modern societies. For literacy, the enforcement is both direct, in the form of mandatory basic education, and indirect, in the form of severe social penalties for failure to acquire reading and writing skills. The dominant cooperative framework (Buchanan et al. 2001) of Western society has developed in such a way that an 
illiterate person is excluded from many opportunities and unable to participate in many aspects of modern life. Despite these enormous and partially coercive pressures, and despite the fact that literacy profoundly changes the way the brain processes language (Petersson 2000), literacy is not deemed to be problematic. The costs of illiteracy are placed on the individual who deliberately avoids education. As social acceptance of other enhancements increases, and if these are available at a reasonable price, it is possible that social support for people who refuse to take advantage of enhancements will diminish.

\section{Inequality}

Concern has been voiced that cognitive enhancements might exacerbate social inequality by adding to the advantages of elites.

To assess this concern one would have to consider whether future cognitive enhancements would be expensive (like good schools) or cheap (like caffeine). One would also have to take into account that there is more than one dimension to inequality. For example, in addition to the gap between the rich and the poor, there is also a gap between the cognitively gifted and the cognitively deficient. One scenario might be that the talent gap decreases because it turns out to be generally easier to enhance individuals at the low end of the performance spectrum than those at the high end whose brains are already functioning close to their biological optimum. There is some tentative support for this in drug studies (Randall et al. 2005). There might thus be a degree of complexity that is often overlooked in the ethical literature on inequality. One should also have to consider under what conditions society might have an obligation to ensure universal access to interventions that improve cognitive performance. An analogy might be drawn to public libraries and basic education (Hughes 2004). Other relevant factors include the speed of technology diffusion, the need for training to achieve full utilization of an enhancement, whether and to what extent/what type of regulation is appropriate, and accompanying public policies. Public policy and regulations can either contribute to inequality by driving up prices, limiting access, and creating black markets; or reduce inequality by supporting broad development, competition, public understanding, and perhaps subsidized access for disadvantaged groups.

Different kinds of enhancements pose different social challenges. A pill that slightly improves memory or alertness is a very different thing than some future radical form of genetic engineering that could lead to the creation of a new "posthuman" human species (Silver 1998; Fukuyama 2002). It has been argued that very powerful enhancements could be placed within a regulatory framework for leveling the playing field if the objective is seen as important enough (Mehlman 2000), but whether the political will to do so will be forthcoming remains to be seen.

It is worth noting that inequality of access to enhancement is a pressing concern only if enhancement confers genuine benefits. Otherwise, as Leon Kass observes, complaining about unequal access to enhancement would be equivalent to objecting that "the food is contaminated, but why are my portions so small (Kass 2003, p. 15)?" 


\section{Discussion: Challenges for Regulation and Public Policy}

"Conventional" means of cognitive enhancement, such as education, mental techniques, neurological health, and external systems, are largely accepted, while "unconventional" means-drugs, implants, direct brain-computer interfaces-tend to evoke moral and social concerns. However, the demarcation between these two categories is problematic and may increasingly blur. It might be the newness of the unconventional means, and the fact that they are currently still mostly experimental, which is responsible for their problematic status rather than any essential problem with the technologies themselves. As society gains more experience with currently unconventional technologies, they may become absorbed into the ordinary category of human tools.

At present, most biomedical enhancement techniques produce, at most, modest improvements of performance (as a rule of thumb, about 10-20\% improvement on typical test tasks). More dramatic results can be achieved using training and humanmachine collaboration, techniques that are less controversial. Mental techniques can achieve $1000 \%$ or more improvement in narrow domains such as specific memorization tasks (Ericsson et al. 1980). While pharmacological cognitive enhancements do not produce dramatic improvements on specific tasks, their effects are often quite general, enhancing performance across a wide domain, such as all tasks making use of working memory or long term memory. External tools and cognitive techniques such as mnemonics, in contrast, are usually task-specific, producing potentially large improvements of relatively narrow abilities. A combination of different methods can be expected to do better than any single method, especially in everyday or workplace settings where a wide variety of tasks have to be performed.

Even small improvements in general cognitive capacities can have important positive effects. Individual cognitive capacity (imperfectly estimated by IQ scores) is positively correlated with income. One study estimates the increase in income from one additional IQ point to $2.1 \%$ for men and 3.6\% for women (Salkever 1995). Higher intelligence is correlated with prevention of a wide array of social and economic misfortunes (Gottfredson 1997, 2004) ${ }^{5}$ and to promote health (Whalley and Deary 2001). Economic models of the loss caused by small intelligence decrements due to lead in drinking water predict significant effects of even a few points change (Salkever 1995; Muir and Zegarac 2001), and it is plausible that a small increment would have positive effects of a similar magnitude. At a societal level, the consequences of many small individual enhancements may be profound. A relatively small upward shift of the distribution of intellectual abilities would substantially reduce the incidence of retardation and learning problems. Such a shift would likely also have important effects on technology, economy, and culture arising from improved performance among high IQ groups.

\footnotetext{
5 There is no link between higher intelligence and more happiness (Sigelman 1981; Hartog and Oosterbeek 1998; Gow et al. 2005). However, see also "Is being intelligent good? Addressing questions of value in behavioural genetics" by Newson (2000) for some more subtle ways intelligence might bring happiness.
} 
Many extant regulations are intended to protect and improve cognitive function. Regulation of lead in paint and tap water, requirements of boxing, bicycle, and motorcycle helmets, bans on alcohol for minors, mandatory education, folic acid fortification of cereals, and sanctions against mothers who abuse drugs during pregnancy all serve to safeguard or promote cognition. To a large extent, these efforts are a subset of general health protection measures, yet stronger efforts appear to be made when cognitive function is at risk. One may also observe that mandated information duties, such as labelling of food products, were introduced to give consumers access to more accurate information in order to enable them to make better choices. Given that sound decision-making requires both reliable information and the cognitive ability to retain, evaluate, and apply this information, one would expect that enhancements of cognition would promote rational consumer choice.

By contrast, we know of no public policy that is intended to limit or reduce cognitive capacity. Insofar as patterns of regulation reflect social preferences, therefore, it seems that society shows at least an implicit commitment to better cognition.

At the same time, however, there exist a number of obstacles to the development and use of cognitive enhancements. One obstacle is the present system for licensing drugs and medical treatments. This system was created to deal with traditional medicine which aims to prevent, diagnose, cure, or alleviate disease. In this framework, there is no room for enhancing medicine. For example, drug companies can find it difficult to get regulatory approval for a pharmaceutical whose sole use is to improve cognitive functioning in the healthy population. To date, every pharmaceutical on the market that offers some potential cognitive enhancement effect was developed to treat some specific pathological condition (such as ADHD, narcolepsy, and Alzheimer's disease). The cognitive enhancing effects of these drugs in healthy subjects constitute a serendipitous unintended benefit. Progress in this area might be accelerated if pharmaceutical companies could focus directly on developing nootropics for use in non-diseased populations rather than having to work indirectly by demonstrating that the drugs are also efficacious in treating some recognized disease.

One of the perverse effects of the failure of the current medical framework to recognize the legitimacy and potential of enhancement medicine is the trend towards medicalization and "pathologization" of an increasing range of conditions that were previously regarded as part of the normal human spectrum. If a significant fraction of the population could obtain certain benefits from drugs that improve concentration, for example, it is currently necessary to categorize this segment of people as having some disease-in this case attention-deficit hyperactivity disorder (ADHD) - in order to get the drug approved and prescribed to those who could benefit from it. This disease-focused medical model will be increasingly inadequate for an era in which many people will be using medical treatments for enhancement purposes.

The medicine-as-treatment-for-disease framework creates problems not only for pharmaceutical companies but also for users ("patients") whose access to enhancers is often dependent on being able to find an open-minded physician who will prescribe the drug. This creates inequities in access. People with high social capital and good information get access while others are excluded. 
The current rise of personalized medicine results both from improved diagnostic methods that provide a better picture of the individual patient, and from the availability of a wider range of therapeutic options which make it necessary to select the one that is most suitable for a particular patient. Many patients now approach their physicians armed with detailed knowledge about their condition and possible treatments. Information can be easily obtained from Medline and other Internet services. These factors are leading to a shift in the physician-patient relationship, away from paternalism to a relationship characterized by teamwork and a focus on the customer's situation. Preventative and enhancing medicine are often inseparable, and both will likely be promoted by these changes and by an increasingly active and informed health care consumer who insists on exercising choice in the medical context. These shifts suggest the need for important and complex regulatory change.

Given that all medical interventions carry some risk, and that the benefits of enhancements may often be more subjective and value-dependent than the benefits of being cured of a disease, it is important to allow individuals to determine their own preferences for tradeoffs between risks and benefits. It is highly unlikely that one size will fit all. At the same time, many will feel the need for a limited degree of paternalism, to protect individuals from at least the worst risks. One option would be to establish some baseline level of acceptable risk in allowable interventions, perhaps by comparison to other risks that society allows individuals to take, such as the risks from smoking, mountain climbing, or horseback riding. Enhancements that could be shown to be no more risky than these activities would be allowed (with appropriate information and warning labels when necessary). Another possibility would be enhancement licenses. People willing to undergo potentially risky but rewarding enhancements could be required to demonstrate sufficient understanding of the risks and the ability to handle them responsibly. This would both ensure informed consent and enable better monitoring. A downside with enhancement licenses is that people with low cognitive capacity, who may have the most to gain from enhancements, could find it hard to get access if the license requirements were too demanding.

Public funding for research does not yet reflect the potential personal and social benefits of many forms of cognitive enhancement. There is funding (albeit perhaps at inadequate levels) for research into education methods and information technology, but not for pharmacological cognitive enhancers. In view of the potentially enormous gains from even moderately effective general cognitive enhancements, this area deserves large-scale funding. It is clear that much research and development are needed to make cognitive enhancement practical and efficient. As discussed above, this requires a change of the view that medicine is only about restoring, not enhancing, capacities, and concomitant changes in the regulatory regime for medical trials and drug approval.

The evidence on prenatal and perinatal nutrition suggests that infant formulas containing suitable nutrients may have a significant positive life-long impact on cognition. Because of the low cost and large potential impact of enriched infant formula if applied at a population level, it should be a priority to conduct more research to establish the optimal composition of infant formula. Regulation could then be used to ensure that commercially available formula contains these nutrients. 
Public health information campaigns could further promote the use of enriched formula that promote mental development. This would be a simple extension of current regulatory practice, but a potentially important one.

There is a wider cultural challenge of destigmatizing the use of enhancers. At present, the taking of medicine is regarded as a regrettable activity, and use of nontherapeutic medication is seen as suspect, possibly misuse. Attempts to enhance cognition are often construed as expression of a dangerous ambition. Yet the border between accepted therapy and suspect enhancement is shifting. Pain relief is now seen as unproblematic. Plastic surgery enjoys ever-wider acceptance. Millions of people ingest nutrient supplements and herbal remedies for enhancing purposes. Self-help psychology is very popular. Apparently, the cultural constructions surrounding the means of enhancement are more important for their acceptance than the actual enhancement ability of these means. To make the best use of new opportunities, society needs a culture of enhancement, with norms, support structures, and a lay understanding of enhancement that takes it into the mainstream cultural context. Consumers also need better information on risks and benefits of enhancers, which suggests a need for reliable consumer information and for more studies to determine safety and efficacy.

Testing of cognitive enhancers would ideally be done not only in the lab but also in field studies that investigate how an intervention works in everyday life. The ultimate criterion of efficacy would be various forms of life success rather than performance in narrow psychological lab tests. Such "ecological testing" would require new kinds of investigation, including monitoring of large sample populations. Advances in wearable computers and sensors may allow unobtrusive monitoring of behavior, diet, use of other drugs, etc. in volunteers. Data mining of collected materials could help determine the effects of enhancers. Such studies, however, would pose major challenges, including cost, new kinds of privacy concerns (monitoring may accumulate information not only about the consenting test subjects but also about their friends and family), and problems of unfair competition if those receiving enhancers experience beneficial effects but others cannot get access to the enhancements due to their experimental nature.

While access to medicine is currently regarded as a human right constrained by cost concerns, it is less clear whether access to all enhancements should or would be regarded as a positive right. ${ }^{6}$ The case for at least a negative right to cognitive enhancement, based on cognitive liberty, privacy interests, and the important interest of persons to protect and develop their own minds and capacity for autonomy, seems very strong. ${ }^{7}$ Banning enhancements would create an inducement for black markets as well as limit socially beneficial uses. Legal enhancement would promote development and use, in the long run leading to cheaper and safer enhancements. Yet without public funding, some useful enhancements may be out of the reach of many. Proponents of a positive right to enhancements could argue for their position on grounds of fairness or equality, or on grounds of a public interest in

\footnotetext{
${ }^{6}$ For an argument that it should, see James Hughes' Citizen Cyborg Why Democratic Societies Must Respond to the Redesigned Human of the Future (Hughes 2004).

7 It can certainly be argued as a negative right (cf. Boire 2001; Sandberg 2003).
} 
the promotion of the capacities required for autonomous agency. The societal benefits of effective cognitive enhancement may even turn out to be so large and unequivocal that it would be Pareto optimal to subsidize enhancement for the poor just as the state now subsidizes education.

Acknowledgements We are grateful to Rebecca Roache for helpful comments on an earlier version of this paper.

\section{References}

Agar, N. (2004). Liberal eugenics: In defence of human enhancement. London: Blackwell Publishing.

Alteheld, N., Roessler, G., Vobig, M., \& Walter, R. (2004). The retina implant new approach to a visual prosthesis. Biomedizinische Technik, 49(4), 99-103.

Antal, A., Nitsche, M. A., Kincses, T. Z., Kruse, W., Hoffmann, K. P., \& Paulus, W. (2004a). Facilitation of visuo-motor learning by transcranial direct current stimulation of the motor and extrastriate visual areas in humans. European Journal of Neuroscience, 19(10), 2888-2892.

Antal, A., Nitsche, M. A., Kruse, W., Kincses, T. Z., Hoffmann, K. P., \& Paulus, W. (2004b). Direct current stimulation over V5 enhances visuomotor coordination by improving motion perception in humans. Journal of Cognitive Neuroscience, 16(4), 521-527.

Bailey, C. H., Bartsch, D., \& Kandel, E. R. (1996). Toward a molecular definition of long-term memory storage. Proceedings of the National Academy of Sciences of the United States of America, 93(24), $13445-13452$.

Banderet, L. E., \& Lieberman, H. R. (1989). Treatment with tyrosine, a neurotransmitter precursor, reduces environmental-stress in humans. Brain Research Bulletin, 22(4), 759-762.

Bao, S. W., Chan, W. T., \& Merzenich, M. M. (2001). Cortical remodelling induced by activity of ventral tegmental dopamine neurons. Nature, 412(6842), 79-83.

Barch, D. M. (2004). Pharmacological manipulation of human working memory. Psychopharmacology, 174(1), 126-135.

Barnes, D. E., Tager, I. B., Satariano, W. A., \& Yaffe, K. (2004). The relationship between literacy and cognition in well-educated elders. Journals of Gerontology Series A, Biological Sciences and Medical Sciences, 59(4), 390-395.

Batejat, D. M., \& Lagarde, D. P. (1999). Naps and modafinil as countermeasures for the effects of sleep deprivation on cognitive performance. Aviation Space and Environmental Medicine, 70(5), 493-498.

Benton, D. (2001). Micro-nutrient supplementation and the intelligence of children. Neuroscience and Biobehavioral Reviews, 25(4), 297-309.

Blair, C., Gamson, D., Thorne, S., \& Baker, D. (2005). Rising mean IQ: Cognitive demand of mathematics education for young children, population exposure to formal schooling, and the neurobiology of the prefrontal cortex. Intelligence, 33(1), 93-106.

Boire, R. G. (2001). On cognitive liberty. The Journal of Cognitive Liberties, 2(1), 7-22.

Bostrom, N. (2003). Human genetic enhancements: A transhumanist perspective. Journal of Value Inquiry, 37(4), 493-506.

Bostrom, N. (2005). In defence of posthuman dignity. Bioethics, 19(3), 202-214.

Bostrom, N., \& Ord, T. (2006). The reversal test: Eliminating status quo bias in bioethics. Ethics, 116(4), 656-680.

Breitenstein, C., Wailke, S., Bushuven, S., Kamping, S., Zwitserlood, P., Ringelstein, E. B., et al. (2004). D-Amphetamine boosts language learning independent of its cardiovascular and motor arousing effects. Neuropsychopharmacology, 29(9), 1704-1714.

Buchanan, A., Brock, D. W., Daniels, N., \& Wikler, D. (2001). From chance to choice. Cambridge: Cambridge University Press.

Butefisch, C. M., Khurana, V., Kopylev, L., \& Cohen, L. G. (2004). Enhancing encoding of a motor memory in the primary motor cortex by cortical stimulation. Journal of Neurophysiology, 91(5), 2110-2116.

Buzan, T. (1982). Use your head. London: BBC Books. 
Caldwell, J. A., Jr., Caldwell, J. L., Smythe, N. K., I. I. I., \& Hall, K. K. (2000). A double-blind, placebocontrolled investigation of the efficacy of modafinil for sustaining the alertness and performance of aviators: A helicopter simulator study. Psychopharmacology (Berl), 150(3), 272-282.

Calef, T., Pieper, M., \& Coffey, B. (1999). Comparisons of eye movements before and after a speedreading course. Journal of the American Optometric Association, 70(3), 171-181.

Cardinali, D. P., Brusco, L. I., Lloret, S. P., \& Furio, A. M. (2002). Melatonin in sleep disorders and jetlag. Neuroendocrinology Letters, 23, 9-13.

Carmena, J. M., Lebedev, M. A., Crist, R. E., O’Doherty, J. E., Santucci, D. M., Dimitrov, D. F., et al. (2003). Learning to control a brain-machine interface for reaching and grasping by primates. PLoS Biology, 1(2), 193-208.

Cattell, R. (1987). Intelligence: It's structure, growth, and action. New York: Elsevier Science.

Chatterjee, A. (2004). Cosmetic neurology-The controversy over enhancing movement, mentation, and mood. Neurology, 63(6), 968-974.

Cochran, G., Hardy, J., \& Harpending, H. (2006). Natural history of Ashkenazi intelligence. Journal of Biosocial Science, 38(5), 659-693.

Craig, I., \& Plomin, R. (2006). Quantitative trait loci for IQ and other complex traits: Single-nucleotide polymorphism genotyping using pooled DNA and microarrays. Genes Brain and Behavior, 5, 3237.

de Quervain, D. J. F., \& Papassotiropoulos, A. (2006). Identification of a genetic cluster influencing memory performance and hippocampal activity in humans. Proceedings of the National Academy of Sciences of the United States of America, 103(11), 4270-4274.

Deijen, J. B., Wientjes, C. J. E., Vullinghs, H. F. M., Cloin, P. A., \& Langefeld, J. J. (1999). Tyrosine improves cognitive performance and reduces blood pressure in cadets after one week of a combat training course. Brain Research Bulletin, 48(2), 203-209.

Diamond, M. C., Johnson, R. E., \& Ingham, C. A. (1975). Morphological changes in young, adult and aging rat cerebral-cortex, hippocampus, and diencephalon. Behavioral Biology, 14(2), 163-174.

Drexler, K. E. (1991). Hypertext publishing and the evolution of knowledge. Social Intelligence, 1(2), $87-120$.

Edelhoff, S., Villacres, E. C., Storm, D. R., \& Disteche, C. M. (1995). Mapping of adenylyl-cyclase genes type-I, type-II, type-III, type-IV, type-V and type-VI in mouse. Mammalian Genome, 6(2), 111-113.

Engelbart, D. C. (1962). Augmenting human intellect: A conceptual framework. Summary report AFOSR3223 under Contract AF 49(638)-1024, SRI Project 3578 for Air Force Office of Scientific Research. Stanford Research Institute: Menlo Park, CA. http://www.dougengelbart.org/pubs/augment3906.html. Accessed 20 April 2009.

Ericsson, A. K. (2003). Exceptional memorizers: Made, not born. Trends in Cognitive Sciences, 7(6), 233-235.

Ericsson, K. A., Chase, W. G., \& Faloon, S. (1980). Acquisition of a memory skill. Science, 208(4448), 1181-1182.

Falls, W. A., Miserendino, M. J. D., \& Davis, M. (1992). Extinction of fear-potentiated startle-Blockade by infusion of an NMDA antagonist into the Amygdala. Journal of Neuroscience, 12(3), 854-863.

Fan, X., Sun, S., McNeese, M., \& Yen, J. (2005). Extending the recognition-primed decision model to support human-agent collaboration. In Proceedings of AAMAS'05, Utrecht, Netherlands (July 25-29).

Fan, X., Sun, S., Yen, J., Sun, B., Airy, G., McNeese, M., Yen, J., Hanratty, T., \& Dumer, J. (2005). Collaborative RPD-enabled agents assisting the three-block challenge in C2CUT. In Proceedings of 2005 conference on behavior representation in modeling and simulation (BRIMS).

Farah, M. J., Illes, J., Cook-Deegan, R., Gardner, H., Kandel, E., King, P., et al. (2004). Neurocognitive enhancement: What can we do and what should we do? Nature Reviews Neuroscience, 5(5), 421-425.

Farrand, P., Hussain, F., \& Hennessy, E. (2002). The efficacy of the 'mind map' study technique. Medical Education, 36(5), 426-431.

Feltz, D. L., \& Landers, D. M. (1983). The effects of mental practice on motor skill learning and performance-A meta-analysis. Journal of Sport Psychology, 5(1), 25-57.

Flynn, J. R. (1987). Massive IQ gains in 14 nations-What IQ tests really measure. Psychological Bulletin, 101(2), 171-191.

Foster, J. K., Lidder, P. G., \& Sunram, S. I. (1998). Glucose and memory: Fractionation of enhancement effects? Psychopharmacology, 137(3), 259-270. 
Fox, P. T., Raichle, M. E., Mintun, M. A., \& Dence, C. (1988). Nonoxidative glucose consumption during focal physiologic neural activity. Science, 241(4864), 462-464.

Frank, R. H., Gilovich, T., \& Regan, D. T. (1993). Does studying economics inhibit cooperation? Journal of Economic Perspectives, 7(2), 159-171.

Fregni, F., Boggio, P. S., Nitsche, M., Bermpohl, F., Antal, A., Feredoes, E., et al. (2005). Anodal transcranial direct current stimulation of prefrontal cortex enhances working memory. Experimental Brain Research, 166(1), 23-30.

Freo, U., Ricciardi, E., Pietrini, P., Schapiro, M. B., Rapoport, S. I., \& Furey, M. L. (2005). Pharmacological modulation of prefrontal cortical activity during a working memory task in young and older humans: A pet study with physostigmine. American Journal of Psychiatry, 162(11), 20612070.

Fukuyama, F. (2002). Our posthuman future: Consequences of the biotechnology revolution. Farrar: Strauss and Giroux.

Gazzaniga, M. S. (2005). The ethical brain. Washington, DC: Dana Press.

Giles, J. (2005). Internet encyclopaedias go head to head. Nature, 438(7070), 900-901.

Gill, M., Haerich, P., Westcott, K., Godenick, K. L., \& Tucker, J. A. (2006). Cognitive performance following modafinil versus placebo in sleep-deprived emergency physicians: A double-blind randomized crossover study. Academic Emergency Medicine, 13(2), 158-165.

Gladstone, D. J., \& Black, S. E. (2000). Enhancing recovery after stroke with noradrenergic pharmacotherapy: A new frontier? Canadian Journal of Neurological Sciences, 27(2), 97-105.

Glover, J. (1984). What sort of people should there be?. New York: Penguin.

Goldstein, L. B. (1999). Amphetamine-facilitated poststroke recovery. Stroke, 30(3), 696-697.

Gottfredson, L. S. (1997). Why G matters: The complexity of everyday life. Intelligence, 24(1), 79-132.

Gottfredson, L. S. (2004). Life, death, and intelligence. Journal of Cognitive Education and Psychology, $4(1), 23-46$.

Gow, A. J., Whiteman, M. C., Pattie, A., Whalley, L., Starr, J., \& Deary, I. J. (2005). Lifetime intellectual function and satisfaction with life in old age: Longitudinal cohort study. British Medical Journal, 331(7509), 141-142.

Greenoug, W. T., \& Volkmar, F. R. (1973). Pattern of dendritic branching in occipital cortex of rats reared in complex environments. Experimental Neurology, 40(2), 491-504.

Gulpinar, M. A., \& Yegen, B. C. (2004). The physiology of learning and memory: Role of peptides and stress. Current Protein \& Peptide Science, 5(6), 457-473.

Hanson, R., Opre, R., \& Porter, D. (2006). Information aggregation and manipulation in an experimental market. Journal of Economic Behavior \& Organization, 60(4), 449-459.

Hanson, R., Polk, C., Ledyard, J., \& Ishikida, T. (2003). The policy analysis market: An electronic commerce application of a combinatorial information market. In Proceedings of ACM conference on electronic commerce 2003, San Diego.

Hartog, J., \& Oosterbeek, H. (1998). Health, wealth and happiness: Why pursue a higher education? Economics of Education Review, 17(3), 245-256.

Healey, J., \& Picard, R. W. (1998). Startlecam: A cybernetic wearable camera. In Proceedings of second international symposium on wearable computing, Pittsburgh, PA.

Helland, I. B., Smith, L., Saarem, K., Saugstad, O. D., \& Drevon, C. A. (2003). Maternal supplementation with very-long-chain N-3 fatty acids during pregnancy and lactation augments children's IQ at 4 years of age. Pediatrics, 111(1), 39-44.

Hofmann, S. G., Meuret, A. E., Smits, J. A. J., Simon, N. M., Pollack, M. H., Eisenmenger, K., et al. (2006). Augmentation of exposure therapy with D-cycloserine for social anxiety disorder. Archives of General Psychiatry, 63(3), 298-304.

Hughes, J. (2004). Citizen Cyborg: Why democratic societies must respond to the redesigned human of the future. Boulder, CO: Westview Press.

Hummel, F. C., \& Cohen, L. G. (2005). Drivers of brain plasticity. Current Opinion in Neurology, 18(6), $667-674$.

Ingvar, M., AmbrosIngerson, J., Davis, M., Granger, R., Kessler, M., Rogers, G. A., et al. (1997). Enhancement by an Ampakine of memory encoding in humans. Experimental Neurology, 146(2), 553-559.

Ioannidis, J. P. A. (2005). Why most published research findings are false. PLoS Medicine, 2(8), 696-701. Iversen, S. D. (1998). The pharmacology of memory. Comptes Rendus De L Academie Des Sciences Serie Iii-Sciences De La Vie-Life Sciences, 321(2-3), 209-215. 
Jackson, P. L., Doyon, J., Richards, C. L., \& Malouin, F. (2004). The efficacy of combined physical and mental practice in the learning of a foot-sequence task after stroke: A case report. Neurorehabilitation and Neural Repair, 18(2), 106-111.

Jebara, T., Eyster, C., Weaver, J., Starner, T., \& Pentland, A. (1997). Stochasticks: Augmenting the Billiards experience with probabilistic vision and wearable computers. In Proceedings of the international symposium on wearable computers. Cambridge, MA.

Johnston, G. (2004). Healthy, wealthy and wise? A review of the wider benefits of education. Report 04/ 04. New Zealand Treasury Working Paper.

Jonas, H. (1985). Technik Medizin Und Ethik: Zur Praxis Des Prinzips Verantwortung. Frankfurt am Main: Suhrkamp.

Kamm, F. (2006). What is and is not wrong with enhancement? KSG working paper RWP06-020. John F. Kennedy School of Government.

Kass, L. (2002). Life, liberty, and defense of dignity: The challenge for bioethics. New York: Encounter Books.

Kass, L. (2003). Ageless bodies, happy souls: Biotechnology and the pursuit of perfection. The New Atlantis, Spring(1), 9-28.

Kennedy, P. R., \& Bakay, R. A. E. (1998). Restoration of neural output from a paralyzed patient by a direct brain connection. NeuroReport, 9(8), 1707-1711.

Kennedy, D. O., Pace, S., Haskell, C., Okello, E. J., Milne, A., \& Scholey, A. B. (2006). Effects of cholinesterase inhibiting sage (Salvia Officinalis) on mood, anxiety and performance on a psychological stressor battery. Neuropsychopharmacology, 31(4), 845-852.

Kilgard, M. P., \& Merzenich, M. M. (1998). Cortical map reorganization enabled by nucleus basalis activity. Science, 279(5357), 1714-1718.

Kincses, T. Z., Antal, A., Nitsche, M. A., Bartfai, O., \& Paulus, W. (2004). Facilitation of probabilistic classification learning by transcranial direct current stimulation of the prefrontal cortex in the human. Neuropsychologia, 42(1), 113-117.

Kleinberg, J. M. (1999). Authoritative sources in a hyperlinked environment. Journal of the ACM, 46(5), 604-632.

Kobayashi, M., Hutchinson, S., Theoret, H., Schlaug, G., \& Pascual-Leone, A. (2004). Repetitive TMS of the motor cortex improves ipsilateral sequential simple finger movements. Neurology, 62(1), 91-98.

Kolnai, A. (1976). Dignity. Philosophy, 51, 251-271.

Korol, D. L., \& Gold, P. E. (1998). Glucose, memory, and aging. American Journal of Clinical Nutrition, 67(4), 764s-771s.

Lashley, K. S. (1917). The effects of strychnine and caffeine upon rate of learning. Psychobiology, 1, $141-169$.

Lee, E. H. Y., \& Ma, Y. L. (1995). Amphetamine enhances memory retention and facilitates norepinephrine release from the hippocampus in rats. Brain Research Bulletin, 37(4), 411-416.

Lieberman, H. R. (2001). The effects of ginseng, ephedrine, and caffeine on cognitive performance, mood and energy. Nutrition Reviews, 59(4), 91-102.

Lieberman, H. R. (2003). Nutrition, brain function and cognitive performance. Appetite, 40(3), $245-254$.

Lorrayne, H. (1996). Page a minute memory book. New York: Ballantine Books.

Lynch, G. (1998). Memory and the brain: Unexpected chemistries and a new pharmacology. Neurobiology of Learning and Memory, 70(1-2), 82-100.

Lynch, G. (2002). Memory enhancement: The search for mechanism-based drugs. Nature Neuroscience, $5,1035-1038$.

Maguire, E. A., Valentine, E. R., Wilding, J. M., \& Kapur, N. (2003). Routes to remembering: The brains behind superior memory. Nature Neuroscience, 6(1), 90-95.

Mann, S. (1997). Wearable computing: A first step toward personal imaging. Computer, 30(2), $25-31$.

Mann, S. (2001). Wearable computing: Toward humanistic intelligence. IEEE Intelligent Systems, 16(3), $10-15$.

Mann, S., \& Niedzviecki, H. (2001). Cyborg: Digital destiny and human possibility in the age of the wearable computer. Canada: Doubleday.

Marshall, L., Molle, M., Hallschmid, M., \& Born, J. (2004). Transcranial direct current stimulation during sleep improves declarative memory. Journal of Neuroscience, 24(44), 9985-9992.

McMorris, T., Harris, R. C., Swain, J., Corbett, J., Collard, K., Dyson, R. J., et al. (2006). Effect of creatine supplementation and sleep deprivation, with mild exercise, on cognitive and psychomotor performance, mood state, and plasma concentrations of catecholamines and cortisol. Psychopharmacology, 185(1), 93-103. 
Meck, W. H., Smith, R. A., \& Williams, C. L. (1988). Prenatal and postnatal choline supplementation produces long-term facilitation of spatial memory. Developmental Psychobiology, 21(4), 339-353.

Mehlman, M. J. (2000). The law of above averages: Leveling the new genetic enhancement playing field. Iowa Law Review, 85(2), 517-593.

Meikle, A., Riby, L. M., \& Stollery, B. (2005). Memory processing and the glucose facilitation effect: The effects of stimulus difficulty and memory load. Nutritional Neuroscience, 8(4), 227-232.

Mellott, T. J., Williams, C. L., Meck, W. H., \& Blusztajn, J. K. (2004). Prenatal choline supplementation advances hippocampal development and enhances MAPK and CREB activation. FASEB Journal, 18(1), 545-547.

Minninger, J. (1997). Total recall. How to boost your memory power. New York: MJF Books.

Mondadori, C. (1996). Nootropics: Preclinical results in the light of clinical effects; comparison with tacrine. Critical Reviews in Neurobiology, 10(3-4), 357-370.

Muir, T., \& Zegarac, M. (2001). Societal costs of exposure to toxic substances: Economic and health costs of four case studies that are candidates for environmental causation. Environmental Health Perspectives, 109, 885-903.

Muller, U., Steffenhagen, N., Regenthal, R., \& Bublak, P. (2004). Effects of modafinil on working memory processes in humans. Psychopharmacology, 177(1-2), 161-169.

Murphy, K. J., Foley, A. G., O’Connell, A. W., \& Regan, C. M. (2006). Chronic exposure of rats to cognition enhancing drugs produces a neuroplastic response identical to that obtained by complex environment rearing. Neuropsychopharmacology, 31(1), 90-100.

Myrick, H., Malcolm, R., Taylor, B., \& LaRowe, S. (2004). Modafinil: Preclinical, clinical, and postmarketing surveillance-A review of abuse liability issues. Annals of Clinical Psychiatry, 16(2), 101-109.

Nava, E., Landau, D., Brody, S., Linder, L., \& Schachinger, H. (2004). Mental relaxation improves longterm incidental visual memory. Neurobiology of Learning and Memory, 81(3), 167-171.

Neisser, U. (1997). Rising scores on intelligence tests. American Scientist, 85(5), 440-447.

Newhouse, P. A., Potter, A., \& Singh, A. (2004). Effects of nicotinic stimulation on cognitive performance. Current Opinion in Pharmacology, 4(1), 36-46.

Newson, A. (2000). Is being intelligent good? Addressing questions of value in behavioural genetics. In Proceedings of 5th world congress of the international association of bioethics. London.

Nicolelis, M. A. L., Dimitrov, D., Carmena, J. M., Crist, R., Lehew, G., Kralik, J. D., et al. (2003). Chronic, multisite, multielectrode recordings in macaque monkeys. Proceedings of the National Academy of Sciences of the United States of America, 100(19), 11041-11046.

Nilsson, M., Perfilieva, E., Johansson, U., Orwar, O., \& Eriksson, P. S. (1999). Enriched environment increases neurogenesis in the adult rat dentate gyrus and improves spatial memory. Journal of Neurobiology, 39(4), 569-578.

Nitsche, M. A., Schauenburg, A., Lang, N., Liebetanz, D., Exner, C., Paulus, W., et al. (2003). Facilitation of implicit motor learning by weak transcranial direct current stimulation of the primary motor cortex in the human. Journal of Cognitive Neuroscience, 15(4), 619-626.

Nyberg, L., Sandblom, J., Jones, S., Neely, A. S., Petersson, K. M., Ingvar, M., et al. (2003). Neural correlates of training-related memory improvement in adulthood and aging. Proceedings of the National Academy of Sciences of the United States of America, 100(23), 13728-13733.

Pascual-Leone, A., Tarazona, F., Keenan, J., Tormos, J. M., Hamilton, R., \& Catala, M. D. (1999). Transcranial magnetic stimulation and neuroplasticity. Neuropsychologia, 37(2), 207-217.

Patil, P. G., Carmena, L. M., Nicolelis, M. A. L., \& Turner, D. A. (2004). Ensemble recordings of human subcortical neurons as a source of motor control signals for a brain-machine interface. Neurosurgery, 55(1), 27-35.

Patten, B. M. (1990). The history of memory arts. Neurology, 40(2), 346-352.

Peterman, M. C., Noolandi, J., Blumenkranz, M. S., \& Fishman, H. A. (2004). Localized chemical release from an artificial synapse chip. Proceedings of the National Academy of Sciences of the United States of America, 101(27), 9951-9954.

Petersson, K. M., Reis, A., Askelof, S., Castro-Caldas, A., \& Ingvar, M. (2000). Language processing modulated by literacy: A network analysis of verbal repetition in literate and illiterate subjects. Journal of Cognitive Neuroscience, 12(3), 364-382.

Pitman, R. K., Sanders, K. M., Zusman, R. M., Healy, A. R., Cheema, F., Lasko, N. B., et al. (2002). Pilot study of secondary prevention of posttraumatic stress disorder with propranolol. Biological Psychiatry, 51(2), 189-192. 
Power, A. E., Vazdarjanova, A., \& McGaugh, J. L. (2003). Muscarinic cholinergic influences in memory consolidation. Neurobiology of Learning and Memory, 80(3), 178-193.

Rae, C., Digney, A. L., McEwan, S. R., \& Bates, T. C. (2003). Oral creatine monohydrate supplementation improves brain performance: A double-blind, placebo-controlled, cross-over trial. Proceedings of the Royal Society of London Series B, Biological Sciences, 270(1529), 2147-2150.

Raine, A., Reynolds, C., Venables, P. H., \& Mednick, S. A. (2002). Stimulation seeking and intelligence: A prospective longitudinal study. Journal of Personality and Social Psychology, 82(4), 663-674.

Randall, D. C., Shneerson, J. M. \& File S. E. (2005). Cognitive effects of modafinil in student volunteers may depend on IQ. Pharmacology Biochemistry and Behavior, 82(1), 133-139.

Raymond, E. S. (2001). The cathedral and the bazaar. Sebastopol, CA: O'Reilly.

Ressler, K. J., Rothbaum, B. O., Tannenbaum, L., Anderson, P., Graap, K., Zimand, E., et al. (2004). Cognitive enhancers as adjuncts to psychotherapy-Use of D-cycloserine in phobic individuals to facilitate extinction of fear. Archives of General Psychiatry, 61(11), 1136-1144.

Rhodes, B., \& Starner, T. (1996). Remembrance agent: A continuously running automated information retrieval system. In Proceedings of the first international conference on the practical application of intelligent agents and multi agent technology (PAAM '96), London.

Routtenberg, A., Cantallops, I., Zaffuto, S., Serrano, P., \& Namgung, U. (2000). Enhanced learning after genetic overexpression of a brain growth protein. Proceedings of the National Academy of Sciences of the United States of America, 97(13), 7657-7662.

Rubinstein, A. (2005). A sceptic's comment on the study of economics. University of Tel Aviv. http://arielrubinstein.tau.ac.il/papers/73.pdf. Accessed 20 April 2009.

Rusted, J. M., Trawley, S., Heath, J., Kettle, G., \& Walker, H. (2005). Nicotine improves memory for delayed intentions. Psychopharmacology (Berl), 182(3), 355-365.

Salkever, D. S. (1995). Updated estimates of earnings benefits from reduced exposure of children to environmental lead. Environmental Research, 70(1), 1-6.

Sandberg, A. (2003). Morphologic freedom. Report \#1. Eudoxa Policy Studies. http://www.eudoxa.se/content/archives/2003/10/eudoxa_policy_s_3.html. Accessed 20 April 2009.

Sandel, M. J. (2002). What's wrong with enhancement. The President's Council on Bioethics. http://www.bioethics.gov/background/sandelpaper.html. Accessed 20 April 2009.

Sandel, M. J. (2004). The case against perfection: What's wrong with designer children, bionic athletes, and genetic engineering. The Atlantic Monthly, 293(4), 51-62.

Savulescu, J. (2001). Procreative beneficence: Why we should select the best children. Bioethics, 15(5-6), 413-426.

Schillerstrom, J. E., Horton, M. S., \& Royall, D. R. (2005). The impact of medical illness on executive function. Psychosomatics, 46(6), 508-516.

Schneider, J. S., Lee, M. H., Anderson, D. W., Zuck, L., \& Lidsky, T. I. (2001). Enriched environment during development is protective against lead-induced neurotoxicity. Brain Research, 896(1-2), 4855.

Sellen, A. J., Louie, G., Harris, J. E., \& Wilkins, A. J. (1996). What brings intentions to mind? An in situ study of prospective memory. Rank Xerox Research Centre Technical Report EPC-1996-104.

Shenoy, K. V., Meeker, D., Cao, S. Y., Kureshi, S. A., Pesaran, B., Buneo, C. A., et al. (2003). Neural prosthetic control signals from plan activity. NeuroReport, 14(4), 591-596.

Sigelman, L. (1981). Is ignorance bliss-A reconsideration of the folk wisdom. Human Relations, 34(11), 965-974.

Silver, L. (1998). Remaking Eden. New York: Harper Perennial.

Singletary, B. A., \& Starner, T. (2000). Symbiotic interfaces for wearable face recognition. In Proceedings of HCII2001 workshop on wearable computing. New Orleans, LA.

Smith, A., Brice, C., Nash, J., Rich, N., \& Nutt, D. J. (2003). Caffeine and central noradrenaline: Effects on mood, cognitive performance, eye movements and cardiovascular function. Journal of Psychopharmacology, 17(3), 283-292.

Snyder, A. W., Bossomaier, T., \& Mitchell, D. J. (2004). Concept formation: 'Object' attributes dynamically inhibited from conscious awareness. Journal of Integrative Neuroscience, 3(1), 31-46.

Snyder, A. W., Mulcahy, E., Taylor, J. L., Mitchell, D. J., Sachdev, P., \& Gandevia, S. C. (2003). Savantlike skills exposed in normal people by suppressing the left fronto-temporal lobe. Journal of Integrative Neuroscience, 2(2), 149-158.

Soetens, E., Casaer, S., Dhooge, R., \& Hueting, J. E. (1995). Effect of amphetamine on long-term retention of verbal material. Psychopharmacology, 119(2), 155-162. 
Soetens, E., Dhooge, R., \& Hueting, J. E. (1993). Amphetamine enhances human-memory consolidation. Neuroscience Letters, 161(1), 9-12.

Stroemer, R. P., Kent, T. A., \& Hulsebosch, C. E. (1998). Enhanced neocortical neural sprouting, synaptogenesis, and behavioral recovery with D-amphetamine therapy after neocortical infarction in rats. Stroke, 29(11), 2381-2393.

Sunram-Lea, S. I., Foster, J. K., Durlach, P., \& Perez, C. (2002). Investigation into the significance of task difficulty and divided allocation of resources on the glucose memory facilitation effect. Psychopharmacology, 160(4), 387-397.

Surowiecki, J. (2004). The wisdom of crowds: Why the many are smarter than the few and how collective wisdom shapes business, economies, societies and nations. New York: Doubleday.

Tan, D. P., Liu, Q. Y., Koshiya, N., Gu, H., \& Alkon, D. (2006). Enhancement of long-term memory retention and short-term synaptic plasticity in Cbl-b null mice. Proceedings of the National Academy of Sciences of the United States of America, 103(13), 5125-5130.

Tang, Y. P., Shimizu, E., Dube, G. R., Rampon, C., Kerchner, G. A., Zhuo, M., et al. (1999). Genetic enhancement of learning and memory in mice. Nature, 401(6748), 63-69.

Teitelman, E. (2001). Off-label uses of modafinil. American Journal of Psychiatry, 158(8), 1341.

The President's Council on Bioethics. (2003). Beyond therapy: Biotechnology and the pursuit of happiness. http://www.bioethics.gov/reports/beyondtherapy/preface.html. Accessed 20 April 2009.

Tieges, Z., Richard Ridderinkhof, K., Snel, J., \& Kok, A. (2004). Caffeine strengthens action monitoring: Evidence from the error-related negativity. Brain Research. Cognitive Brain Research, 21(1), 87-93.

Tomporowski, P. D. (2003). Effects of acute bouts of exercise on cognition. Acta Psychologica, 112(3), 297-324.

Trachtenberg, J. (2000). The Trachtenberg speed system of basic mathematics. London: Souvenir Press.

Turner, D. C., Robbins, T. W., Clark, L., Aron, A. R., Dowson, J., \& Sahakian, B. J. (2003). Cognitive enhancing effects of modafinil in healthy volunteers. Psychopharmacology, 165(3), 260-269.

van Beek, T. A. (2002). Chemical analysis of Ginkgo Biloba leaves and extracts. Journal of Chromatography. A, 967(1), 21-55.

Vaynman, S., \& Gomez-Pinilla, F. (2005). License to run: Exercise impacts functional plasticity in the intact and injured central nervous system by using neurotrophins. Neurorehabilitation and Neural Repair, 19(4), 283-295.

von Wild, K., Rabischong, P., Brunelli, G., Benichou, M., \& Krishnan, K. (2002). Computer added locomotion by implanted electrical stimulation in paraplegic patients (SUAW). Acta Neurochirurgica. Supplementum, 79, 99-104.

Walsh, R. N., Budtz-Olsen, O. E., Penny, J. E., \& Cummins, R. A. (1969). The effects of environmental complexity on the histology of the rat hippocampus. The Journal of Comparative Neurology, 137(3), 361-365.

Wang, H. B., Ferguson, G. D., Pineda, V. V., Cundiff, P. E., \& Storm, D. R. (2004). Overexpression of type-1 adenylyl cyclase in mouse forebrain enhances recognition memory and LTP. Nature Neuroscience, 7(6), 635-642.

Warburton, D. M. (1992). Nicotine as a cognitive enhancer. Progress in Neuro-Psychopharmacology and Biological Psychiatry, 16(2), 181-191.

Warwick, K., Gasson, M., Hutt, B., Goodhew, I., Kyberd, P., Andrews, B., et al. (2003). The application of implant technology for cybernetic systems. Archives of Neurology, 60(10), 1369-1373.

Watanabe, A., Kato, N., \& Kato, T. (2002). Effects of creatine on mental fatigue and cerebral hemoglobin oxygenation. Neuroscience Research, 42(4), 279-285.

Wei, F., Wang, G. D., Kerchner, G. A., Kim, S. J., Xu, H. M., Chen, Z. F., et al. (2001). Genetic enhancement of inflammatory pain by forebrain NR2B overexpression. Nature Neuroscience, 4(2), $164-169$.

Weiser, M. (1991). The computer for the twenty-first century. Scientific American, 265(3), 94-110.

Wenk, G. (1989). An hypothesis on the role of glucose in the mechanism of action of cognitive enhancers. Psychopharmacology, 99, 431-438.

Whalley, L. J., \& Deary, I. J. (2001). Longitudinal cohort study of childhood IQ and survival up to age 76. British Medical Journal, 322(7290), 819-822.

Wilkinson, L., Scholey, A., \& Wesnes, K. (2002). Chewing gum selectively improves aspects of memory in healthy volunteers. Appetite, 38(3), 235-236.

Winder, R., \& Borrill, J. (1998). Fuels for memory: The role of oxygen and glucose in memory enhancement. Psychopharmacology, 136(4), 349-356. 
Winship, C., \& Korenman, S. (1997). Does staying in school make you smarter? The effect of education on IQ in the bell curve. In B. Devlin, S. E. Fienberg, \& K. Roeder (Eds.), Intelligence, genes, and success: Scientists respond to the bell curve (pp. 215-234). New York: Springer.

Wolpaw, J. R., Birbaumer, N., Heetderks, W. J., McFarland, D. J., Peckham, P. H., Schalk, G., et al. (2000). Brain-computer interface technology: A review of the first international meeting. IEEE Transactions on Rehabilitation Engineering, 8(2), 164-173.

Yates, F. (1966). The art of memory. Chicago: University of Chicago Press.

Zhou, M. F., \& Suszkiw, J. B. (2004). Nicotine attenuates spatial learning lead deficits induced in the rat by perinatal exposure. Brain Research, 999(1), 142-147. 